\title{
Movements of green sturgeon, Acipenser medirostris, in the San Francisco Bay estuary, California
}

\author{
John T. Kelly ${ }^{\text {a }}$, A. Peter Klimley ${ }^{\mathrm{a}} \&$ Carlos E. Crocker ${ }^{\mathrm{b}}$ \\ ${ }^{a}$ Department of Wildlife, Fish \& Conservation Biology, University of California, One Shields Avenue, Davis, \\ CA 95616, USA (e-mail: jtkelly@ucdavis.edu) \\ ${ }^{\mathrm{b}}$ Department of Biology, San Francisco State University, 1600 Holloway Avenue, San Francisco, CA 94132 , \\ $U S A$
}

Received 1 July $2005 \quad$ Accepted 1 February 2006

Key words: ultrasonic telemetry, acipenserids, tracking, directional movement

\section{Synopsis}

The green sturgeon, Acipenser medirostris, is a long-lived, iteroparous, anadromous acipenserid that is native to the San Francisco Bay Estuary, California. Sub-adult and adult fish are oceanic, but enter the estuary during the spring and remain through autumn. Little is known about green sturgeon distribution within the estuary or what, if any, physical parameters influence their movements. We report the results of a telemetry study conducted between September 2001 and November 2002. Five sub-adult and one adult green sturgeon were captured by trammel net in the San Pablo Bay region of the estuary. We implanted depth-sensing, ultrasonic transmitters within the peritoneum of individuals and tracked them from a boat for $1-15 \mathrm{~h}$ per day over periods ranging from 1 to 12 days. Salinity, temperature, and dissolved oxygen profiles of the water column were measured hourly. Observed movements were categorized as either nondirectional or directional. Non-directional movements, accounting for $63.4 \%$ of observations, were closely associated with the bottom, with individuals moving slowly while making frequent changes in direction and swim speed, or not moving at all. Directional movements consisted of continuous swimming in the top $20 \%$ of the water column while holding a steady course for extended periods. Four of the five sub-adult fish remained within the confines of San Pablo Bay for the duration of their tracking period. The remaining sub-adult moved over $45 \mathrm{~km}$ up-river into Suisun Bay before contact was lost. The adult fish exited the bay and entered the ocean $6 \mathrm{~h}$ after release near Tiburon, CA, a movement of approximately $10 \mathrm{~km}$. The subadult fish typically remained at the shallower depths $(<10 \mathrm{~m})$ of the estuary, but there were no apparent preferences for temperature, salinity, or dissolved oxygen, with the fish moving widely and rapidly across the range of these physical parameters. Activity is believed to be independent of light level with no discernable crepuscular, nocturnal, or diurnal peaks in activity.

\section{Introduction}

The green sturgeon, Acipenser medirostris, is one of two sturgeon species native to Californian waters. While a sizeable body of literature exists on their sister taxon, the white sturgeon,
A. transmontanus, little is known about the green sturgeon, which is smaller and less common than its congeners, and of negligible commercial value. Like other sturgeons, green sturgeon are large, long-lived, anadromous, and iteroparous (Moyle 2002). They may attain lengths in excess of $3 \mathrm{~m}$ 
and have a potential lifespan in excess of 50 years. ${ }^{1,2}$ Green sturgeon are considered highly anadromous, more so than other acipenserids, spending extended periods of their life in the temperate regions of the Pacific Ocean along the west coast of North America (Erickson \& Hightower in press).

Adults are known to spawn in the freshwater rivers of California and Oregon (Erickson et al. 2002, Moyle 2002). Genetic analyses (Israel et al. 2004) separate green sturgeon into at least two distinct populations: a northern population which spawns in small coastal rivers such as the Klamath (California) and Rogue (Oregon), and a southern population which spawns in the Sacramento River system of California and often inhabits the Columbia and Willapa estuaries in Washington, though it is not believed to spawn in those rivers. Mature adults move into estuaries in the spring, and continue into natal rivers to spawn between spring and early summer (Moyle 2002) depending on the river system. The spawning season on the Rogue River, which lacks a large, well-defined estuary, is April through May (Erickson \& Webb this volume). Age at first reproduction is thought to be $15-17$ years for males and 20-25 years for females (J. Van Eenennaam, University of California, Davis, Department of Animal Science, personal communication), with repeated spawning thought to occur every 2-4 years (Erickson \& Webb this volume).

Larvae develop within freshwater rivers, moving to the estuaries early in the first year, where they may remain for approximately 3 years before migrating to the ocean. ${ }^{3}$ Post-spawning adults in the northern population remain in the river over the summer before returning to the ocean when river temperatures drop below $10^{\circ} \mathrm{C}$ and water flow increases with the onset of the first winter storms (Erickson et al. 2002). It is not currently known if adults of the southern population also

\footnotetext{
${ }^{1}$ Nakamoto, R.J., T.T. Kisanuki \& G.H. Goldsmith. 1995. Age and growth of Klamath River green sturgeon (Acipenser medirostris). U.S. Fish and Wildlife Service Report 93-FP-13. Yreka, CA.

${ }^{2}$ Farr, R.A., M.L. Hughes, \& T.A. Rien. 2002. Green sturgeon population characteristics in Oregon. Oregon Department of Fish and Wildlife Fish Research Project Annual Report F178-R.

${ }^{3}$ Nakamoto et al. 1995
}

follow this pattern or if they first return to the estuary to forage before migrating back to the ocean in the late fall or early winter. Sub-adult fish and non-spawning adults have also been observed in Pacific coast estuaries during summer and fall months, although they do not continue upstream into the river systems (D. Erickson, Wildlife Conservation Society \& J. Kelly, University of California, Davis, unpublished data). Adults are believed to migrate northward during the winter months. ${ }^{4}$

Our knowledge about green sturgeon feeding habits is meager, though they are believed to be primarily opportunistic benthic foragers due to the sub-terminal placement of their mouth and the diets of congeners. Stomach content analysis by Radtke (1966) and Ganssle (1966) suggests that juvenile green sturgeon in San Francisco Bay feed primarily on benthic crustaceans, particularly amphipods, Corophium spp., Photis californica, shrimp, Neomysis spp., Crangon fransciscorum, isopods, Synidotea laticauda, as well as clams, Macoma spp., annelid worms, and unidentified crabs and fishes. The diet of adults is not well documented.

The goal of this project was to describe the behavior and movements of green sturgeon in the San Francisco Estuary. To address this, six green sturgeons were intensively tracked during late summer and early fall of 2001 and 2002 when the species was expected to be in the region. We expected that the movements of this species would be confined within a preferred range of physical water characteristics, such as temperature, salinity, and dissolved oxygen. Additionally, we predicted that green sturgeon would be largely benthic based on their morphology, and nocturnally active based on the observed behavior of captive reared green sturgeon juveniles (J.J. Cech Jr., Department of Wildlife, Fish \& Conservation Biology, University of California, Davis, personal communication).

\footnotetext{
${ }^{4}$ Adams, P.B., C.B. Grimes, J.E. Hightower, S.T. Lindley \& M.L. Moser. 2002. Status review for North American Sturgeon, Acipenser medirostris. National Marine Fisheries Service, Santa Cruz, California. Available from the Internet URL http:// www.nwr.noaa.gov/1salmon/salmesa/pubs/GSstatus_review.pdf
} 


\section{Methods}

Green sturgeon were captured in San Pablo Bay (Figure 1) using trammel nets deployed from the $R / V$ Striper II, operated by the California Department of Fish and Game during their ongoing white sturgeon mark-recapture study. One meter of total length (TL) was set as the minimum size based on tag size and available space in the peritoneal cavity. Fish were thought to be adult if they exceeded $145 \mathrm{~cm}$ TL (Erickson \& Webb in press). Fish gender was not determined.

When a green sturgeon of acceptable size was captured, it was transferred immediately to our research boat, which was standing by to receive fish. Fish captured in 2001 (GS1 and GS2) were transported by boat to the nearby Romberg Tiburon Center (RTC) in Tiburon, CA, where the fish were surgically implanted with depth-sensing, ultrasonic transmitters (Sonotronics, DT-97). The

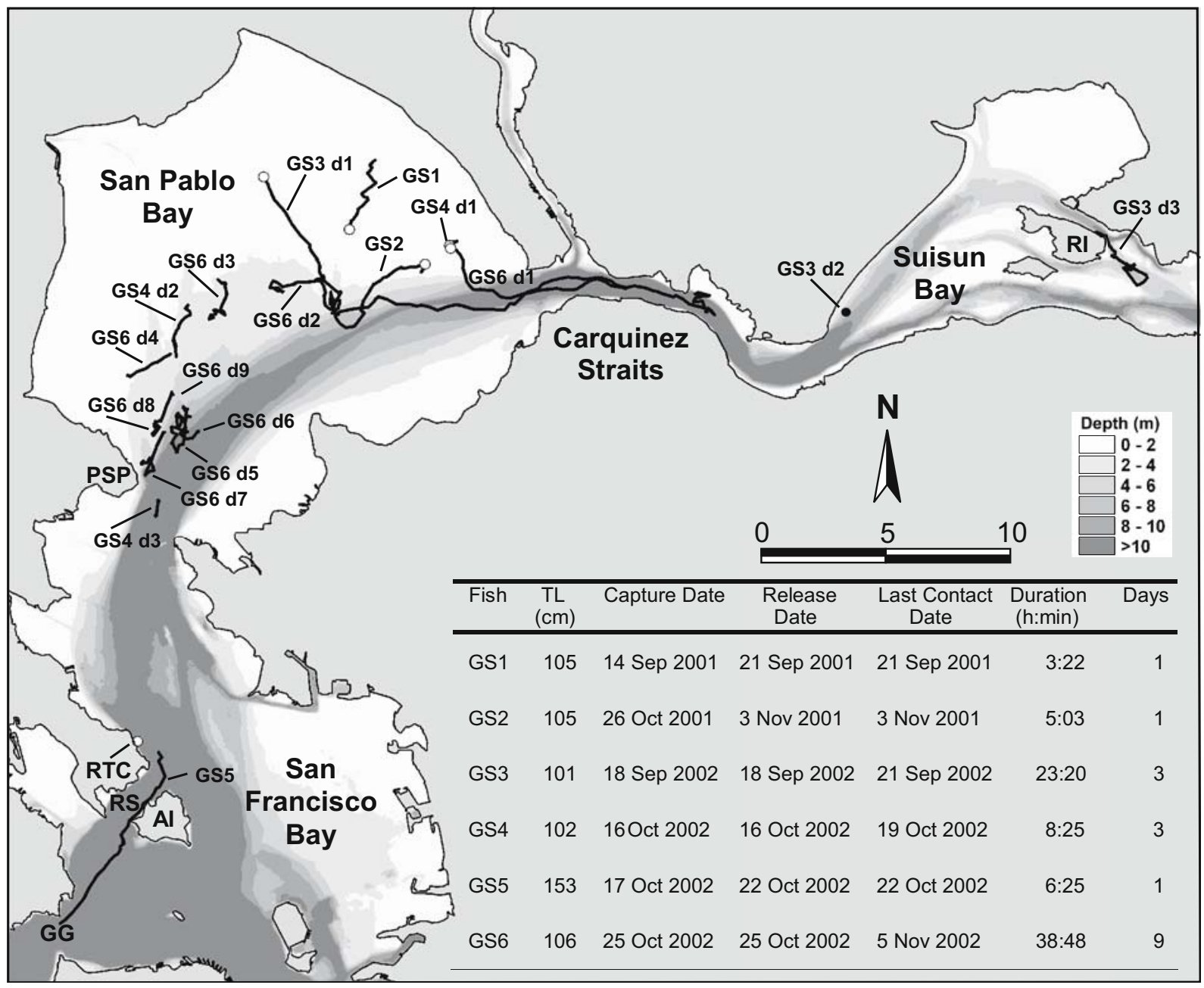

Figure 1. Study area in the San Francisco Estuary including northern San Francisco Bay, San Pablo Bay, and Suisun Bay, California. Tracks of individual green sturgeon are indicated by black lines and labeled with fish number and tracking day (e.g., GS3 d1 = green sturgeon \#3, first day), open circles indicate release location. AI = Angel Island, GG = Golden Gate, PSP $=$ Point San Pedro, RI = Ryer Island, RS = Raccoon Strait, RTC = Romberg Tiburon Center (San Francisco State University). Inset Table: Summary of green sturgeon tagged and tracked in 2001-2002 indicating total length (TL), capture date and location, release date, date of final contact with fish, total duration of all tracks, number of days tracked. Note: all fish were released at the point of capture except GS5 which was captured in San Pablo Bay, transported to RTC and released directly from that facility. 
transmitter was cylindrical $(11 \mathrm{~mm}$ diameter and $34 \mathrm{~mm}$ length), weighed $19 \mathrm{~g}$ in water, had a 360 day battery life, and was uniquely coded by frequency and pulse number. Surgery was conducted by inverting the fish and placing it in a vinyl-cloth stretcher. The head and eyes were covered to reduce stress and the gills ventilated with a continuous flow of bay water. The incision site was swabbed with iodine solution (Povidone Iodine USP $10 \%$ solution) and a small incision $(3 \mathrm{~cm})$ was made through the body wall, offset from the midline and adjacent to the third or fourth ventral scute, based on the method described by Moser and Ross (1995). The sterilized tag was inserted into the peritoneal cavity and the incision sutured closed with three or four individual knotted sutures of 1-0 polydioxanone monofilament (Ethicon, PDS*II). Fish were allowed to recover in tanks supplied with natural, flowthrough water for 3 days post-surgery and transported back to the point of capture for release.

In 2002, a new protocol was used in order to minimize our effect on the natural movements of the fish. GS3, GS4 and GS6 were internally tagged as before, but the surgery was conducted on our research boat at the site of capture. Post-surgery, fish were immediately returned to the bay waters and held at the surface until they swam away under their own power. For logistical reasons, GS5 was transported to RTC, held for 5 days in a tank supplied with natural, flow-through water, and tagged and released adjacent to the lab, about $20 \mathrm{~km}$ from the capture site. The salinity of the water adjacent to RTC was approximately $31 \mathrm{ppt}$, slightly more saline ( $5 \mathrm{ppt}$ ) than the water at the site of capture. Fish tagged in 2002 were implanted with a different transmitter (Vemco Ltd., V22XP) due to prior difficulties with detection range and data decoding. This tag was cylindrical $(22 \mathrm{~mm}$ diameter and $120 \mathrm{~mm}$ length), weighed $40 \mathrm{~g}$ in water, had a depth range of $0-34 \mathrm{~m}$, a battery life of 10 days, and was uniquely coded by frequency. The Vemco tags were detected with a directional hydrophone and an ultrasonic receiver at ranges in excess of $4 \mathrm{~km}$ (DuKane Corp., N30ASB) and telemetry data received and decoded at ranges of up to $1 \mathrm{~km}$ (Vemco Ltd., VR-60). All six fish tagged in this project swam-off under their own power and resumed active movements, and there were no known mortalities.
Tracking of tagged fish commenced immediately upon release utilizing the 'ground zero' method described by Nelson (1987). Briefly, this method entails following the fish in a boat using a directional hydrophone to locate the tag signal. The boat is maneuvered as close to the fish as possible, and the location of the boat is recorded at 10-s intervals on a GPS-equipped laptop PC, which also decodes and stores the depth data received from the tag. Because one is actually recording the position of the boat in this method, the recorded positions were approximations of the location of the sturgeon, and include minor spatial error caused by drift due to winds, current, and the difficulty of positioning the boat precisely over the sturgeon. If the raw data were plotted directly, the track would imply more movement on the part of the fish than actually took place. To address this, the raw data must be filtered at a time interval that minimizes error while retaining movement data. An interval of 5 min was determined as optimal for this project using the method described in detail by Klimley et al. (2005) and was used to calculate movement vectors (bearing and distance traveled) for each track.

At hourly intervals during each track, the salinity, temperature, and dissolved oxygen were measured throughout the water column with a water quality sonde (Hydrolab, Surveyor II). Measurements were recorded at the surface, the bottom (or the end of the $25-\mathrm{m}$ cable), and regular intervals in between (at 1-m increments if bottom depth was $<10 \mathrm{~m}, 3-\mathrm{m}$ increments when depth $>10 \mathrm{~m}$ ). The profile of the entire water column was interpolated from these records and the physical properties of the environment experienced by the fish were estimated according to the depth recorded by the tag at the time of each profile. Due to the low number of sturgeon tracked $(N=6)$ and non-normal distributions, inferential statistical tests were not performed on these data; however, the data were graphed and descriptive statistics were calculated.

Daily tracking occurred for several continuous hours, as weather conditions permitted; however, the strong winds and rough surface conditions that are common in this area during the summer evening hours limited tracking periods. Fish were relocated, if possible, on subsequent days and tracking continued until each tagged fish was lost, 
we were unable to relocate the fish, or the tag ceased to transmit, at which point a new fish was captured, tagged, and tracked.

The geographical coordinates and telemetered swimming depth of the sturgeon were entered into a geographic information system (ESRI, ArcView 3.2) and overlaid onto a 5-m grid, digital elevation model of the bathymetry of the San Francisco Estuary, prepared by the California Department of Fish and Game, Information Technology Division, GIS Service Center, Sacramento, California.

The directionality of movements was described and tested using circular statistic software (Kovach Computing Services, Oriana 2.00) using Rayleigh's concentration coefficient $(r)$ as a measure of the angular directionality of the vectors in each section of a track (Zar 1998). Values for ' $r$ ' range from ' 0 ', indicating that the headings are uniformly distributed, to ' 1 ', when all of the headings are in the same direction. Significance was tested using Rayleigh's test $(\alpha=0.05)$.

\section{Results}

Six green sturgeon were tracked in the San Francisco Estuary during the fall months of 2001 and 2002 (Figure 1). Five fish were sub-adult $(\mathrm{GS} 1-4,6$, range $=101-106 \mathrm{~cm} ;$ mean $=104 \mathrm{~cm}$ TL) and one (GS5, $153 \mathrm{~cm}$ TL) was believed to be an adult (Figure 1 inset table). Tracks lasted between 1 and $15.25 \mathrm{~h}$ per day for up to 9 days within a 12-day period. GS1 was released on 21 September 2001 within San Pablo Bay and was tracked for a period of $3 \mathrm{~h} 22 \mathrm{~min}$ in shallow water until severe weather conditions ended the track. GS2 was released on 3 November in western San Pablo Bay. It moved slowly and erratically for approximately $2 \mathrm{~h}$ before starting to swim rapidly in the deep water channel in the bay. Contact with GS2 was lost after 5 h 2 min of tracking. We were not able to relocate either GS1 or GS2 after the initial track. GS3 was tagged and released in the northern end of San Pablo Bay on 18 September 2002. The fish moved minimally on the bottom for $2 \mathrm{~h} 10 \mathrm{~min}$ before conducting a lengthy movement into the deep water channel of the estuary and up into the Carquinez Straits. This movement lasted until the track was broken off $13 \mathrm{~h} 5$ min later on
19 September near the entrance to Suisun Bay. GS3 was relocated on 20 September at the southwestern end of Suisun Bay and again the following day well inside the bay near Ryer Island, at which time it was tracked for a further $8 \mathrm{~h} 10 \mathrm{~min}$. We were unable to relocate GS3 in subsequent days and believe it moved into the complex network of sloughs that comprise the Sacramento/San Joaquin River Delta. GS4 was tagged 16 October 2002 in the shallow western end of San Pablo Bay and tracked for $5 \mathrm{~h} 15 \mathrm{~min}$ during which time the fish moved minimally. This fish was found $11.9 \mathrm{~km}$ from the point of release on 18 October and tracked for $2 \mathrm{~h} 20 \mathrm{~min}$, then tracked again for $50 \mathrm{~min}$ on 19 October, $5.8 \mathrm{~km}$ farther south. GS5 was captured on 17 October 2002 in San Pablo Bay, while the search for GS4 was still underway. We were not prepared to tag the fish at that time, so it was transported to a holding tank at RTC. It was released adjacent to that facility on 22 October whereupon it swam rapidly and directly out of the bay into the ocean, traveling $10 \mathrm{~km}$ over a $6 \mathrm{~h}$ 24 min period, and was never located again. GS6 was tagged on 25 October 2002 in western San Pablo Bay and tracked for $2 \mathrm{~h} 45 \mathrm{~min}$ as it conducted a directional movement into the Carquinez Straits, similar to that performed by GS3. GS6 was relocated in the middle of San Pablo Bay on 27 October and tracked daily in that region through 1 November, then again on 3 and 5 November for a total of 9 days over the 12-day period.

The observed movements of green sturgeon were categorized as directional or non-directional. Directional movements were typified by continuous and active swimming while holding a steady course for long periods of time, as illustrated by the track of GS5 (Figure 2a). This fish was released near RTC at 11:40, and promptly swam slowly along the shoreline following a nearshore current before circling in a large eddy at the end of the Tiburon Peninsula during the late flood tide at 13:05. Slack tide occurred at 13:49 with ebb building thereafter. At 14:55 the fish entered the out-going water current passing through Raccoon Strait between the Tiburon Peninsula and Angel Island, moving swiftly and strongly ahead of the current, at an average speed of $0.8 \mathrm{~m} \mathrm{~s}^{-1}$, before exiting through the Golden Gate $9 \mathrm{~km}$ away at 18:05. The track was aborted at this location due to unsafe boating conditions. 

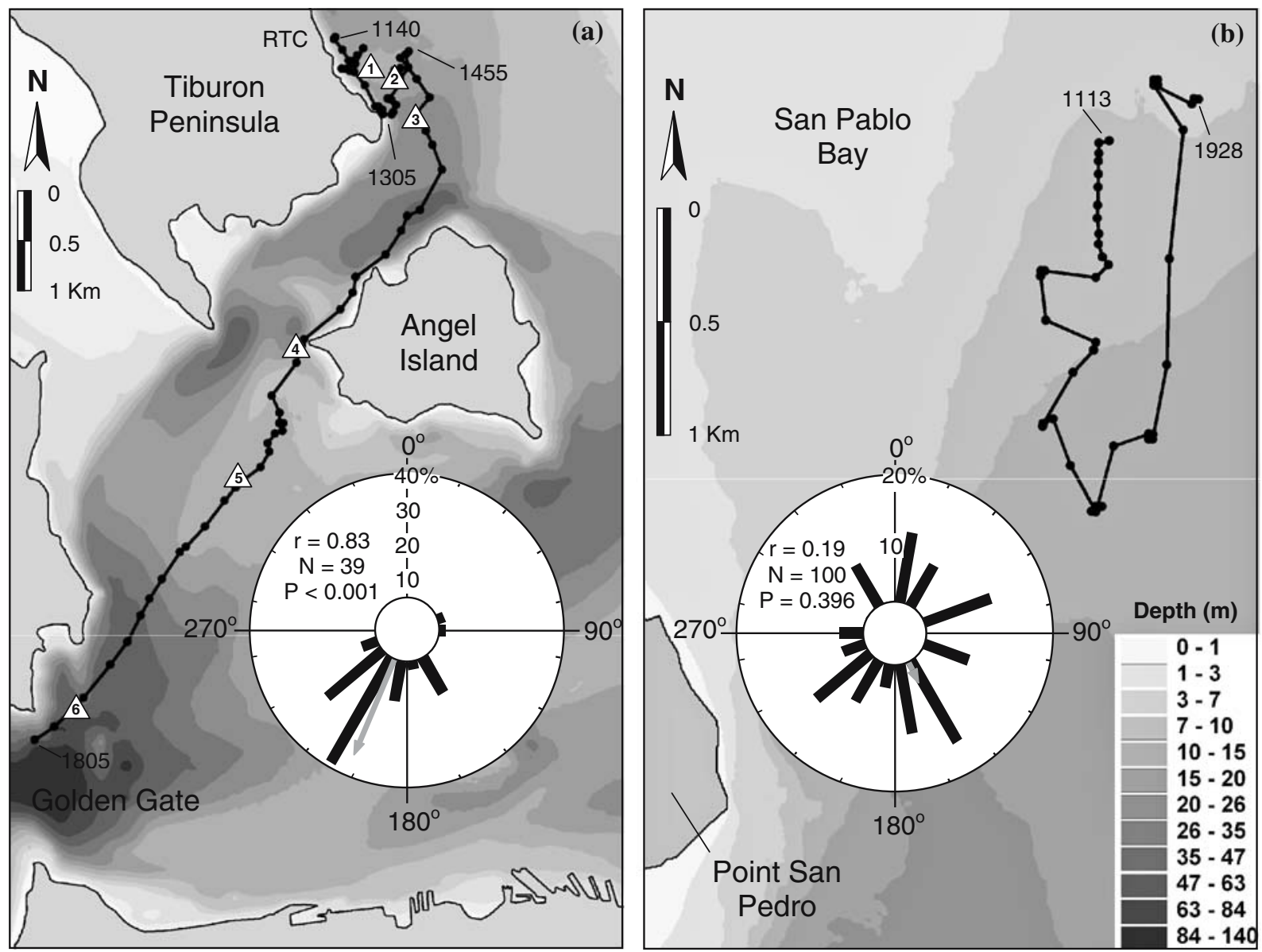

Figure 2. Examples of green sturgeon moving (a) directionally (GS5 during 22 Oct 2002) and (b) non-directionally (GS6 during 30 Oct 2002). Black dots indicate positions at 5-min intervals (note scale differences between a and b), lines are vectors indicating movement between those points. Insets: circular histogram of movement vectors for each track showing degree of concentration of movement vectors around a mean angle (gray arrow). The length of the arrow reflects the degree of concentration (Rayleigh's $r$ ). The numbered triangles in (a) indicate locations of water column sampling for temperature, salinity, and dissolved oxygen.

Movement vectors in this track were highly directional. The Rayleigh's $r$ coefficient for the entire track, including the time spent in the eddy, was $0.45(N=78, p<0.001)$; omitting movements associated with the eddy increased $r$ to 0.83 $(N=39, p<0.001)$, with a mean movement bearing of $203^{\circ}$.

Directional movements were observed in 5 out of 6 fish and accounted for $36.6 \%$ of total observations. The longest single movement was conducted by GS3, which covered $22.5 \mathrm{~km}$ during a 13-h 5-min period (15:25-04:30 h) between 18 September and 19 September $2002 \quad(r=0.52$, $N=112, p<0.001)$. Only GS4 was never observed making directional movements; however, its location was separated by $11.9 \mathrm{~km}$ on two subsequent tracks, suggesting a directional movement had occurred in the interim. The Rayleigh's $r$ for the five fish observed during directional movements ranged over $0.34-0.83$ and were all directional according to Rayleigh's test $(p<0.005)$. These fish were typically observed to move in the same direction as the prevailing current, actively swimming faster than the speed of the current. Movements and orientation with respect to current are under analysis and will be presented in a future publication.

The total rate of movement over ground during directional movements averaged $0.56 \mathrm{~m} \mathrm{~s}^{-1}$ $\left(N=378, \mathrm{SD}=0.48\right.$, range $\left.0.00-2.20 \mathrm{~m} \mathrm{~s}^{-1}\right)$ with 
$17.5 \%$ of the movements in excess of $1.00 \mathrm{~m} \mathrm{~s}^{-1}$. When moving directionally, green sturgeon were typically observed to swim near the top of the water column. For example, when the depth of GS5 is compared to the bottom depth (Figure 3a) it is clear that the fish swam in the upper $2 \mathrm{~m}$ of the water column and rarely ventured below $5 \mathrm{~m}$, despite the depth of the bottom exceeding $20 \mathrm{~m}$ during four fifths of the duration of the track.
When all depth records from the directional movements of all tracked fish are grouped and the depths normalized according to the proportion of the water column the fish were using (Figure 4), it is apparent that green sturgeon make directional movements near the surface, with $49.2 \%$ of movements occurring in the top $20 \%$ of the water column. Note that there were times when fish were found near the bottom during directional move-
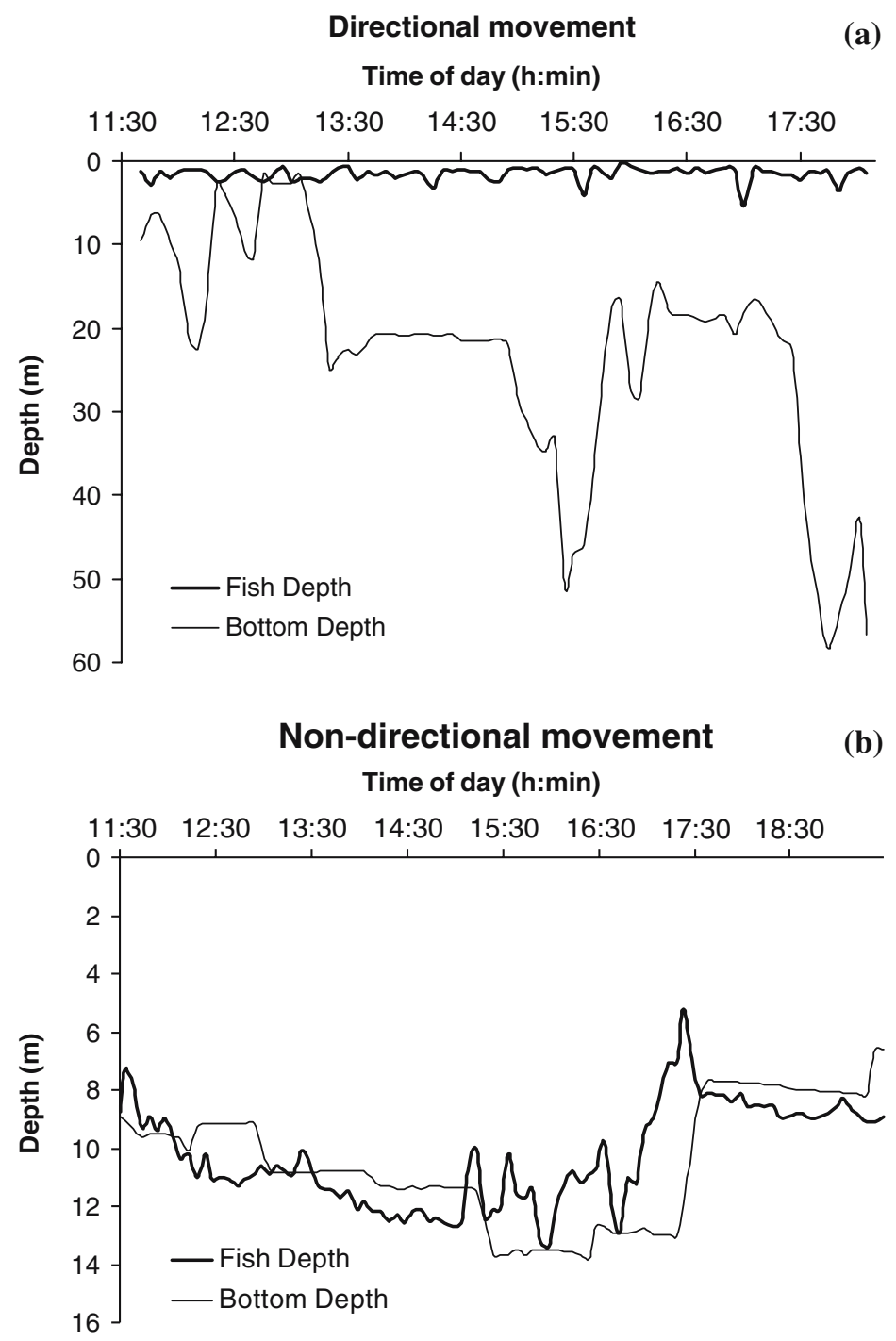

Figure 3. Green sturgeon dive profiles during (a) directional (GS5, 22 Oct 2002) and (b) non-directional movement (GS6, 30 Oct 2002). The swimming depths (thick line) were transmitted from tags implanted in the fish, whereas bottom depths (thin line) were measured at the position of the boat. In areas where there are large changes in depth over short distances, small differences between the locations of the fish and boat result in the fish appearing to be below the bay bottom. This is particularly evident when the fish are swimming along the edge of the channel within the bay (b, see location of same track in Figure 1). 


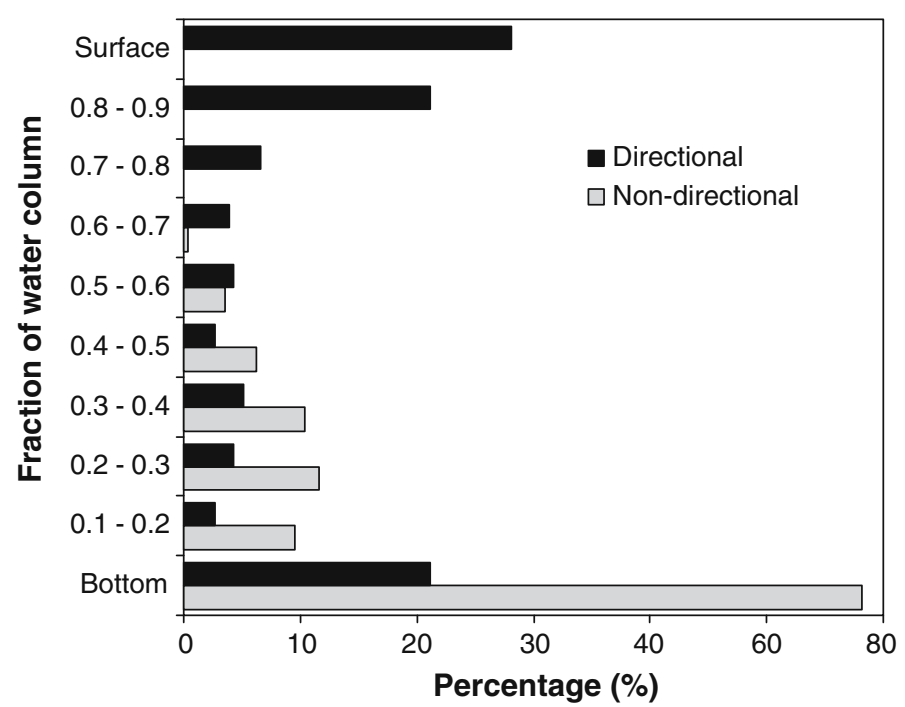

Figure 4. Comparison of the percentage of time that tracked green sturgeon swam in different fractions of the water column (ranging from 0 for bottom to 1 for surface) during directional (black bars) and non-directional (gray bars) movements.

ments; however, in these instances, the fish were moving in shallow water $(2-3 \mathrm{~m}$ depth).

During non-directional movements, fish were either stationary or moved slowly making frequent changes in direction, as in the track of GS6 between 11:13 and 19:28 on 30 October 2002 (Figure 2b). During the course of this 8-h track, the fish did not move farther than $2 \mathrm{~km}$ and ended close to where the track began. The Rayleigh's $r$ for GS6 during this period was $0.19(N=100$, $p=0.396$ ), which does not differ from random movement. This behavior was observed during ebb, flood, and slack phases of the semi-diurnal mixed tidal cycles in the estuary, and appeared to be unrelated to these changing conditions. For example, the period of the track referenced above (GS6, 30 October 2002) encompassed two tidal changes, starting during flood, continuing through the ebb at 12:46, and into the flood tide again starting at 18:07.

Non-directional movements were observed in five of six fish and accounted for $63.4 \%$ of all observations. Only GS5 moved continuously for the entire track with no recorded stationary phase. The total rate of movement over ground during non-directional movements averaged $0.21 \mathrm{~m} \mathrm{~s}^{-1}$ $\left(N=635, \mathrm{SD}=0.31\right.$, range $\left.0.00-1.94 \mathrm{~m} \mathrm{~s}^{-1}\right)$ with only $3.3 \%$ of the movements in excess of $1.00 \mathrm{~m} \mathrm{~s}^{-1}$. During non-directional movements, the sturgeon were closely associated with the bottom. For example, the depth record from GS6 on 30 Oct 2002 (Figure 3b) indicates the fish was largely between $8-12 \mathrm{~m}$, which correlates with local bathymetry. Note that the, depth reported for the fish was measured by the tag in its peritoneum, while the depth of the bottom was recorded below the boat. In areas with complex bathymetry, small differences in position between fish and boat may place the boat in shallower water than the fish and result in the fish appearing to below the bay bottom, particularly when swimming close to the edge of a channel (see path of GS6 in Figure 1).

Our ability to track fish was biased by weather and few tracks were recorded during the evening and at night. Dusk and night tracking data are available from only three tracks of two fish (GS3 and GS6). The rates of movement from these tracks were plotted against time of day to determine if diel activity patterns could be distinguished (Figure 5). The movements of these two fish appear to be independent of light level with no discernable crepuscular, nocturnal, or diurnal changes in movement $\left(R^{2}=0.07\right)$.

Sturgeon ranged widely throughout the bay, encountering diverse environmental conditions during their movements. The bottom depths over which the fish moved ranged between 1.7 and $58.4 \mathrm{~m}($ mean $=8.8 \mathrm{~m})$ with fish recorded swimming at depths between 0.3 and $24.3 \mathrm{~m}$ $($ mean $=5.3 \mathrm{~m})$ (Figure 6$)$. In general, the sturgeon 


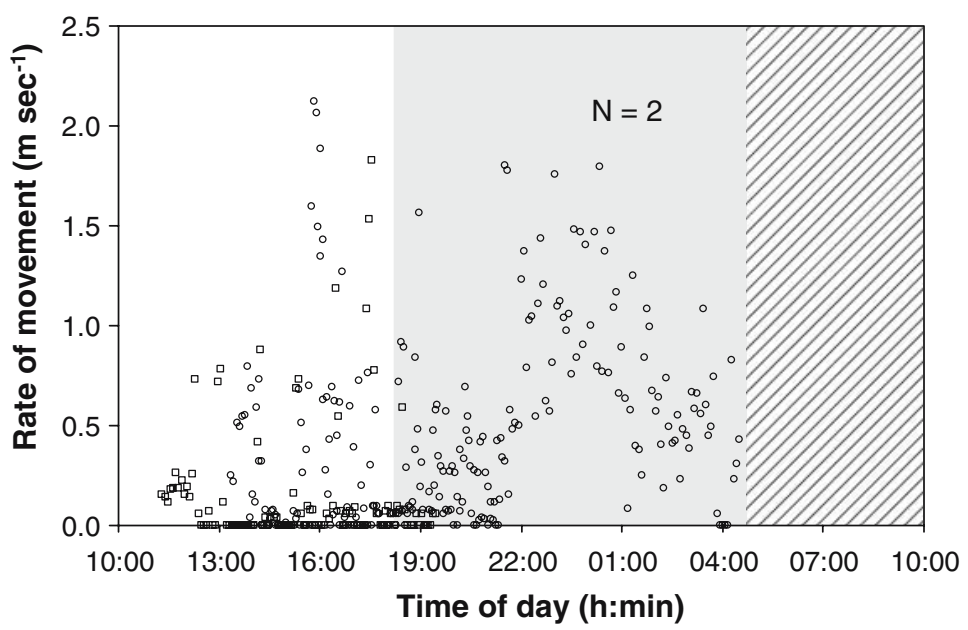

Figure 5. Rate of movement ( $\mathrm{m} \mathrm{s}^{-1}$ ) of green sturgeons GS3 (circles) and GS6 (squares) from days when tracking was conducted after dark, plotted as a function of time of day. Gray shading indicates approximate night-time hours based on the beginning and end of nautical twilight, crosshatching indicates absence of sampling. Note that sturgeon remained stationary, swam slowly, and rapidly both during daytime and night-time.

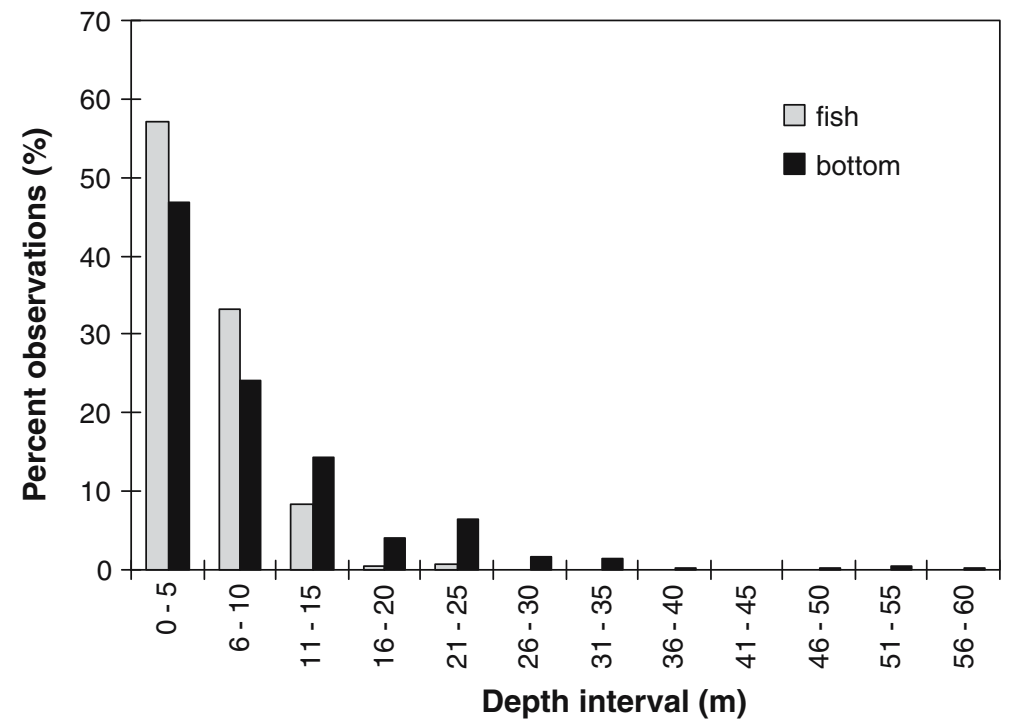

Figure 6. Depth distribution of green sturgeon tracked in the San Francisco Estuary. Gray bars represent the depths at which fish were recorded, black bars represent the bottom depths over which the fish swam during the course of the tracks.

remained in shallow regions of the bay, with $70.9 \%$ of their time spent swimming over bottom depths of $<10 \mathrm{~m}$.

The estuary is vertically well-mixed, with no apparent thermo-, halo-, or oxyclines. For example, six profiles are presented in Figure 7 that were recorded during the track of GS5 (refer to Figure $2 \mathrm{a}$ for specific locations). Values in the measured parameters varied minimally for any given water column profile, with average ranges of $0.4^{\circ} \mathrm{C}, 1.2 \mathrm{ppt}$, and $0.67 \mathrm{mg} \mathrm{O}_{2} \mathrm{l}^{-1}$, respectively. Temperatures in the water column recorded during all tracks combined ranged from 14.5 to $21.9^{\circ} \mathrm{C}$, and fish were recorded at values ranging between 14.5 and $20.8^{\circ} \mathrm{C}($ mean $=16.8, \mathrm{SD}=2.0)$. Salinities in the water column ranged from 8.4 to $32.4 \mathrm{ppt}$, 


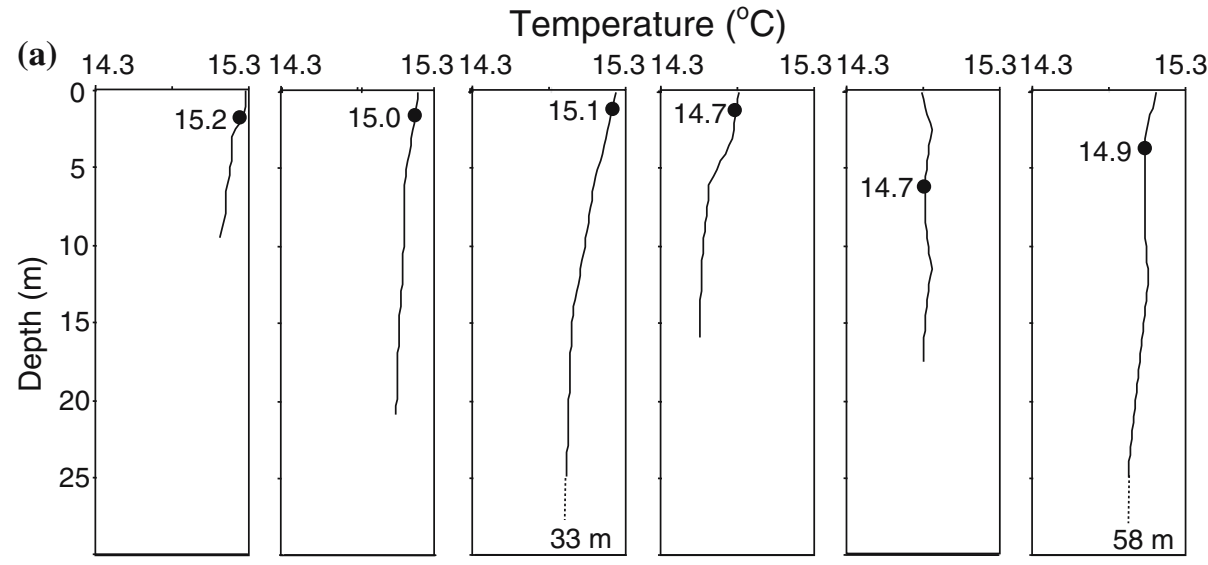

(b)

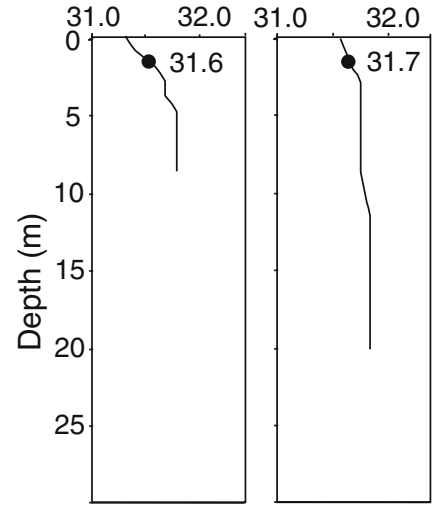

Salinity (ppt)

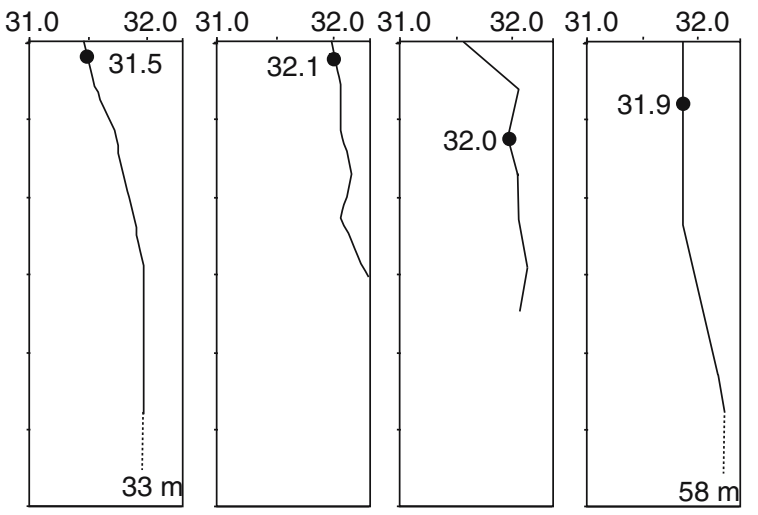

(c)

Dissolved Oxygen $\left(\mathrm{mg} \mathrm{O}_{2} \mathrm{~L}^{-1}\right)$
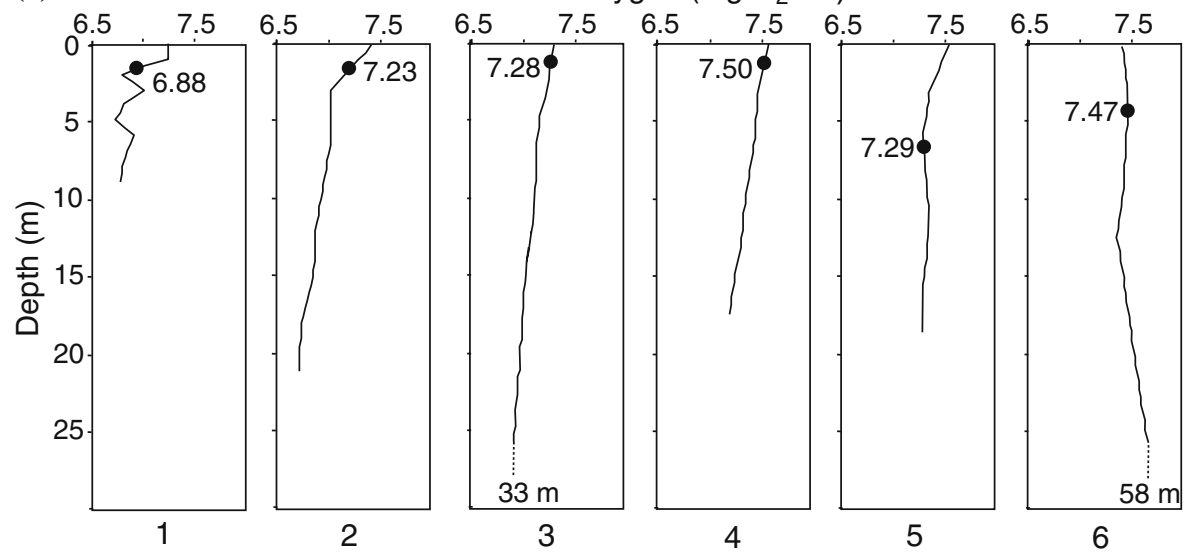

Water Column Profile

Figure 7. Series of water column profiles of (a) temperature, (b) salinity, and (c) dissolved oxygen recorded during the track of GS5 on 22 Oct 2002 (see numbered triangles in Figure 2a for locations). Approximately $1 \mathrm{~h}$ separated subsequent profiles: (1) 12:45 h, (2) 14:03 h, (3) 15:05 h, (4) 16:00 h, (5) 17:00 h, and (6) 18:00 h. Measurements of these environmental properties were recorded from the surface to the bottom (or the end of the $25 \mathrm{~m}$ cable) at intervals of $1-3 \mathrm{~m}$. The dashed line indicates bottom depth when it exceeded cable length. The solid circles indicate the depths at which GS5 was swimming when the column profile was recorded. 
and fish were recorded at values ranging between 8.8 and $32.1 \mathrm{ppt}($ mean $=25.5, \mathrm{SD}=5.4)$. There was no apparent difference between the distributions of mean column temperatures and salinities and the values where the fish were located (Figure $8 \mathrm{a}$ and $\mathrm{b}$ ). The mean dissolved oxygen (DO) content of the water column ranged from
6.26 to $9.70 \mathrm{mg} \mathrm{O}_{2} \mathrm{1}^{-1}$, while the fish were recorded at values ranging between 6.54 and $8.98 \mathrm{mg} \mathrm{O}_{2} \mathrm{l}^{-1}$ (mean $=7.69, \mathrm{SD}=0.45)$. There is an apparent slight difference between the distributions of mean column DO vs. the levels fish selected (Figure 8c) with fish found an average of $0.68 \mathrm{mg} \mathrm{O}_{2} 1^{-1}$ lower than the mean column value.
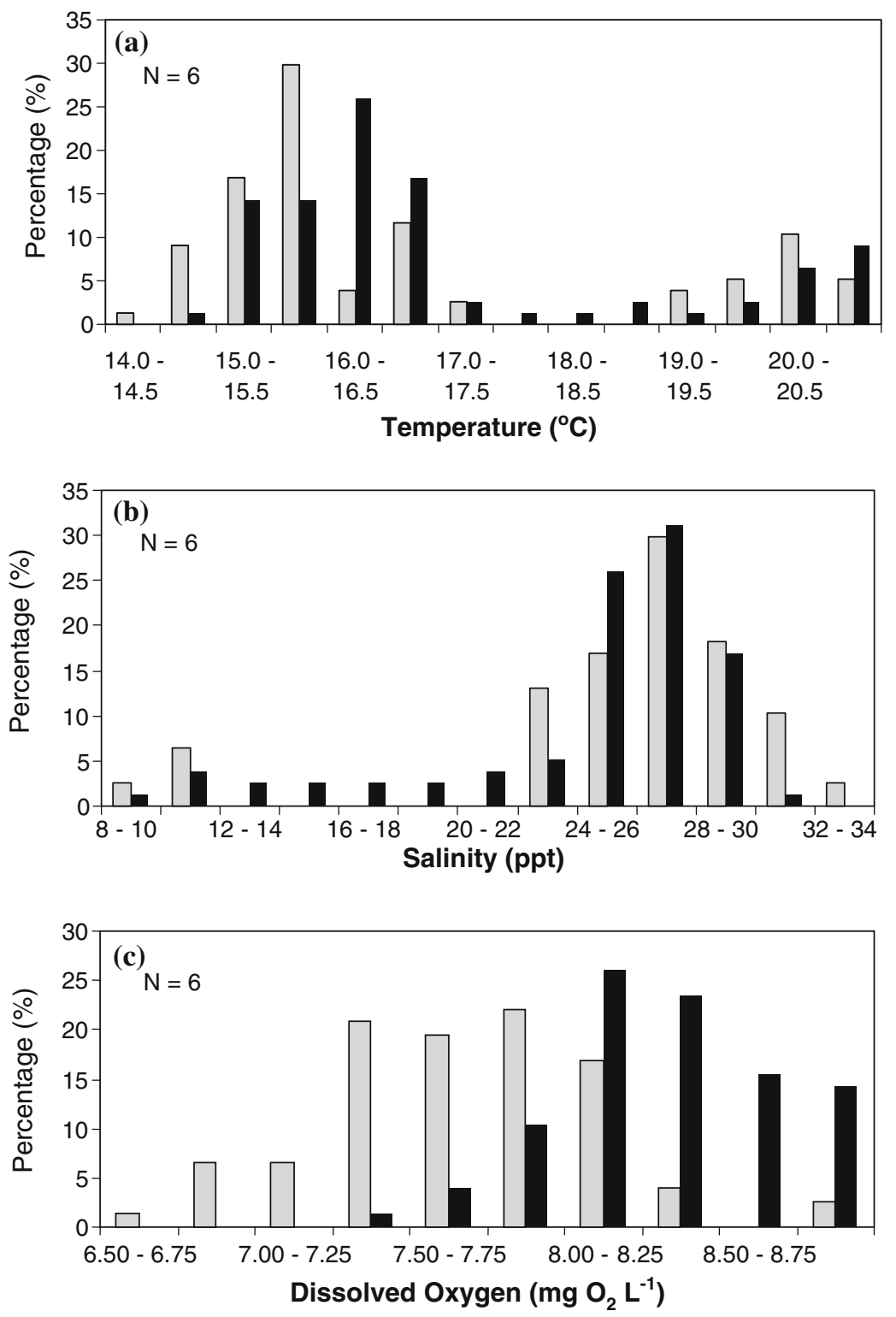

Figure 8. Histograms compiled from all tracks comparing the physical properties of the water in the bay experienced by the fish (gray bars) and the mean value for the entire water column (black bars) at the time of each depth profile for (a) temperature, (b) salinity, and (c) dissolved oxygen. 


\section{Discussion}

The movements of green sturgeon in the San Francisco Bay Estuary are not purely random. Two distinct modes of movement were observed, directional and non-directional. Most commonly, individual fish remained for long periods of time in small areas, moving slowly and erratically on or near the substrate. Green sturgeon are typically considered a benthic species due to the sub-terminal position of the mouth and overall morphology, and this was corroborated during our observations of non-directional movement. Without direct observation - which was not possible in the highly turbid waters of the estuary - we could not precisely determine what the fish were doing at these times; however, such behavior is consistent with the fish foraging in areas of high prey abundance.

Less frequently, the fish moved actively covering long distances in a continuous, rapid, and directional manner. In contrast to the benthic orientation observed during non-directional movement, when moving directionally the fish were found in the highest portion of the water column (Figure 4). This surface-oriented swimming was unexpected and intriguing. For example GS5 remained almost entirely within $2 \mathrm{~m}$ of the surface (Figure 3a), and once was even observed breaking the surface with its rostrum, despite traveling over depths in excess of $55 \mathrm{~m}$. All fish that moved directionally exhibited this surface-oriented swimming suggesting that there is some factor associated with the surface that influences this behavior. It is possible that visual or electrosensory cues important to orienting within the bay are available at the surface that are not available at depth. Surface-oriented movement has been observed in many oceandwelling fishes and is thought to facilitate orientation to celestial or geomagnetic cues (see review in Klimley et al. 2002). Notably, adult green sturgeon tracked in the ocean did not appear to move at the surface, though they did make occasional rapid vertical ascents (Erickson \& Hightower in press), which may have been for the purpose of orientation.

The long duration and directional fidelity of these movements indicates that they are not random, though their purpose is unclear and may differ between individuals. Movements were observed in both directions (towards-river and towards-ocean), once even exiting the bay. Because the majority of movements recorded in this study were made by sub-adults, they may have been related to the acquisition of better food resources. Sub-adults are thought to remain in the bay for a number of years feeding and growing before beginning their oceanic phase (see discussion in Moyle 2002). If the green sturgeon's prey in the estuary is distributed patchily, the observed directional movements may have been either ranging behavior in search of a new patch, or possibly intentional navigation to a different known patch. This combination of lengthy periods of localized, non-directional movement interspersed with occasional long distance movements has also been noted in juvenile Atlantic sturgeon, A. oxyrinchus oxyrinchus, (Moser \& Ross 1995), and Gulf sturgeon, A. o. desotoi, (Sulak \& Clugston 1999, Fox et al. 2002). Both Sulak \& Clugston (1999) and Fox et al. (2002) argued that these patterns are indicative of fish searching for prey and lingering to forage in areas of suitable prey abundance.

The one fish that physically left the bay (GS5) was thought to be an adult based on its size. Because the individual was never detected again, and the late-fall timing of the movement, we believe that the recorded movement was the onset of the fall migration out of the estuary and into the coastal ocean. An alternate explanation is that GS5 received the most handling of the six tagged animals and was translocated within the bay prior to release, and therefore may not have been behaving normally. However, four of the other fish also performed directional movements, what differed in this instance was that GS5 exited the estuary. Nothing else about this fish's behavior differed from the other tracks.

There appeared to be no relation between activity level and time of day in the green sturgeon we observed. It must be cautioned that due to the hazards of operating a small boat in this region, our effort was biased toward mid-day with fewer evening and night-time tracks. Consequently, there was a significant portion of the day during which sturgeon could not be tracked and physical measurements could not be collected. However, during the periods when we tracked sturgeon (10:0004:30), individuals were observed to not move, move slowly, and move rapidly both during day 
and night, and with no discernable peaks. An absence of diel activity patterns was also reported in Atlantic sturgeon (Moser \& Ross 1995). This is contrary to what was expected based on the apparent nocturnal activity of captive-reared green sturgeon juveniles (J.J. Cech Jr., Department of Wildlife, Fish \& Conservation Biology, University of California, Davis, personal communication). Kynard et al. (2005) also reported nocturnal activity peaks in both larval green sturgeon and 9to 10-month-old juveniles, attributing it as an adaptation for avoiding predation during dispersal migration and first-year wintering. The reported nocturnal behavior of reared fish may be specific to younger individuals, who would normally still be inhabiting the river environment, or it may be an artifact of captive rearing. The fish we tracked larger than $1 \mathrm{~m}$ TL and living in the estuary faced entirely different predation pressures and may have gained no benefit from being nocturnal. Interestingly, Erickson and Hightower (in press), described an apparent increase in activity at night in adult green sturgeon inhabiting the coastal ocean. These observations suggest that nocturnal behavior in this species may be habitat and lifestage dependent.

We were unable to clearly parse out preferred habitats (shallow or deep, high or low relief, etc.) because of limited sample size, though preference for specific habitats may exist. In their study on the estuarine habitat usage of the congeneric Gulf sturgeon, Fox et al. (2002) noted that the fish were primarily found in shallow water (between 2 and $4 \mathrm{~m}$ ) and rarely in the deeper waters of the estuary. While green sturgeon were occasionally found at depths up to $24.3 \mathrm{~m}$, they too generally avoided the deepest waters, spending the majority of their time in the shallower regions of the estuary at a mean depth of $5.3 \mathrm{~m}$.

Initially, we expected that the movements of green sturgeon in the San Francisco Estuary would be influenced by physical parameters of the water column and that the fish would move to remain within preferred ranges of temperature, salinity, and DO; however, this was not the case. The estuary within the study area is vertically well mixed with no apparent regions of abrupt change. There were only minute differences in the ranges in the measured parameters, and it is doubtful that differences of this magnitude are physiologically significant enough for sturgeon to need to move vertically to select specific conditions.

The tracked fish ranged widely in the estuary from the warm, shallow, brackish areas in Suisun Bay to the colder, deeper, oceanic region near the Golden Gate. The distribution of temperatures and salinities at the depths at which fish were tracked did not differ markedly from the distribution of the means, which is expected if movement was independent of physical gradients. This suggests that green sturgeon were not actively responding to temperature on salinity, but rather their movements were initiated in response to and/ or directed by other factors. Oddly, there was a measurable difference in the oxygen concentration levels at which the fish were recorded when compared to the mean values; mean DO where fish occurred was lower than the mean column value. We believe this is an artifact of the sturgeon occupying the bottom where the DO is typically lower, rather than seeking out lower DO. Bottom DO values, while measurably lower than those at the surface, were still within $90-95 \%$ of surface saturation values indicating that the estuary is well-mixed and normoxic. Differences of this magnitude are not physiologically meaningful to fish and should have minimal influence on the ability of green sturgeon to fully oxygenate their arterial blood (Kaufman et al., in press). It is possible that different results would be found in estuaries that are more stratified or have greater extremes in these physical properties.

One of the most notable findings was how rapidly the fish could move through a wide salinity range. For example, GS3 was tagged in San Pablo Bay on 18 September 2002, and was tracked during a 13-h, 5-min, $22.5 \mathrm{~km}$ up-river movement into the Carquinez Straits. The mean water column salinity at the start was $24.9 \mathrm{ppt}$. The salinity when the track was terminated near Benicia, CA, was 22.1 ppt. The same fish was relocated on 21 September 2002, $20 \mathrm{~km}$ farther up-river in Suisun Bay off of the eastern end of Ryer Island, and tracked again for over $8 \mathrm{~h}$. The measured salinity at the end of this track was 8.7 ppt. We were unable to relocate GS3 after this day, and we believe it moved farther into the freshwater sloughs of the Sacramento River delta. In the span of 3 days, GS3 moved in excess of $45 \mathrm{~km}$, and experienced a change in environmental salinity of at least 
$16.2 \mathrm{ppt}$, while moving from highly brackish water into almost fresh water. These findings are similar to those of Fox et al. (2002), who reported the rapid transition of two Gulf sturgeon from the freshwater river environment to brackish bay waters over a $>120 \mathrm{~km}$ distance in a span of 4 days. This suggests that the habitat tolerance ranges of adult green sturgeon are wide and adaptable and that their movements may be limited only by extreme conditions

\section{Summary}

Green sturgeon move throughout much of the San Francisco Estuary, and often make significant long-distance movements throughout the region. The movements are not random, rather they show distinct directionality. These movements did not appear to be related to the measured gradients in temperature, salinity, and dissolved oxygen within the bay. Consistent with its being an anadromous fish and possessing a fully oceanic phase of its lifecycle, green sturgeon were observed to be tolerant of a broad range of environmental conditions. It is likely that the species' movements and distribution are due to other factors such as resource availability. Additional larger scale studies are required to understand the timing and scope of movements into and out of the estuary and rivers for the purposes of foraging, spawning and refuge.

\section{Acknowledgements}

We dedicate this article to the memory of Arthur A. Myrberg Jr., Professor of Marine Biology and Fisheries at the University of Miami, FL, who inspired generations of scientists - including the authors (JTK, APK) - to devote their lives to studying the behavior of marine organisms. This research was funded by a grant from the Anadromous Fish Restoration Program (co-implemented by the United States Fish and Wildlife Service and the Bureau of Reclamation). GIS bathymetry data were provided by W. Patterson, California Department of Fish and Game, Information Technology Division, GIS Service Center,
Sacramento, California. This project would not have been possible without the efforts of N. Kogut, R. Schaffter, D. Kohlhorst, M. Silva, and the field staff of the CDFG Bay/Delta Branch. Thanks also to J. Cech, R. Kihslinger, S. Lankford, V. Wunderlich and all those that volunteered their time and efforts. The manuscript benefited from reviews by S. Bolden, J. Cech, M. Gard, and E. Schmitt.

\section{References}

Erickson, D.L. \& J.E. Hightower. Oceanic distribution and behavior of green sturgeon. In: J. Munro, D. Hatin, K. McKown, J. Hightower, K. Sulak, A. Kahnle \& F. Caron (eds.), Proceedings of the Symposium on Anadomous Sturgeon: Status and Trends, Anthropogenic Impacts and Essential Habitats. American Fisheries Society (in press).

Erickson, D.L., J.A. North, J.E. Hightower, J. Weber \& L. Lauck. 2002. Movement and habitat use of green sturgeon, Acipenser medirostris, in the Rogue River, Oregon, USA. J. Appl. Ichthyol. 18: 565-569.

Erickson, D.L., \& M.A.H. Webb. In Press. Spawning periodicity, spawning migration, and size at maturity of green sturgeon, Acipenser medirostris, in the Rogue River, Oregon. Environ. Biol. Fishes.

Fox, D.A., J.E. Hightower \& F.M. Parauka. 2002. Estuarine and nearshore marine habitat use by gulf sturgeon from the Choctawhatchee River system, Florida. Am. Fish. Soc. Symp. 28: 111-126.

Ganssle, D. 1966. Fishes and decapods of San Pablo and Suisun Bays. pp. 64-94. In: D.W. Kelley (ed.), Ecological Studies of the Sacramento-San Joaquin Estuary, Part I. California Department of Fish and Game Fish Bulletin 133.

Israel, J.A., J.F. Cordes, M.A. Blumberg \& B. May. 2004. Geographic patterns of genetic differentiation among collections of green sturgeon. North Am. J. Fish. Manage. 24: 922 931.

Kaufman, R.C., A.G. Houck \& J.J. Cech. Effects of temperature and carbon dioxide on green sturgeon blood-oxygen equilibria. Environ. Biol. Fishes 00: 000-000 (In press).

Klimley, A.P., S.C. Beavers, T.H. Curtis \& S.J. Jorgensen. 2002. Movements and swimming behavior of three species of sharks in La Jolla Canyon, California. Environ. Biol. Fishes 63: 117-135.

Klimley, A.P., R.L. Kihslinger \& J.T. Kelly. 2005. Directional and non-directional movements of bat rays, Myliobatis californica, in Tomales Bay, California. Environ. Biol. Fishes 74: 79-88.

Kynard, B., E. Parker \& T. Parker. 2005. Behavior of early life intervals of Klamath River green sturgeon, Acipenser medirostris, with a note on body color. Environ. Biol. Fishes 72 : 85-97.

Moser, M.L. \& S.W. Ross. 1995. Habitat use and movements of shortnose and Atlantic sturgeons in the lower Cape Fear 
River, North Carolina. Transac. Am. Fish. Soc. 124: 225234.

Moyle, P.B. 2002. Inland Fishes of California. University of California Press, Berkeley. 502 pp.

Nelson, D. 1987. The use of ultrasonic tracking in telemetry studies. pp. 118-129. In: W.F. Herrnkind \& A.B. Thistle (eds.), Signposts in the Sea: Proceedings of a Multidisciplinary Workshop on Marine Animal Orientation and Migration: 29-31 May 1986, FSU. Tallahassee, FL, 210 pp.

Radtke, L.D. 1966. Distribution of smelt, juvenile sturgeon, and starry flounder in the Sacramento-San Joaquin Delta with observations on food of sturgeons. pp. 115-119. In: J.L.
Turner \& D.W. Kelley (eds.), Ecological Studies of the Sacramento-San Joaquin Estuary, Part II. California Department of Fish Game Fish Bulletin 136.

Sulak, K.J. \& J.P. Clugston. 1999. Recent advances in the life history of Gulf of Mexico sturgeon, Acipenser oxyrinchus desotoi, in the Suwannee River, Florida, USA: A synopsis. J. Appl. Ichthyol. 15: 116-128.

Zar, J.H. 1998. Biostatistical Analysis. 4th edition. Prentice Hall, New Jersey. 929 pp. 